\title{
Los materiales y medios didácticos del Departamento de Geografía de la UNED
}

\author{
Rufino Prieto Carretero
}

Me propongo como tarea realizar algunas reflexiones personales sobre cómo valorar o chequear los materiales y medios didácticos.

Tratar de valorar y hablar sobre los materiales didácticos de nuestro Departamento no es fácil para mí, $1 .^{\circ}$ ) porque no soy el autor de estos materiales, $2^{\circ}$ ) porque, aun no siendo el autor de ellos, sí que comparto muchísimo de la filosofía de sus objetivos, contenidos, metodología, etc.

Con todo ello, me voy a atrever a decir algunas cosas, confiando en que, aunque sólo sea por discrepancia con lo que digo, pueda generar la discusión y el debate.

Al reflexionar sobre esta cuestión de los materiales, la primera duda que me surgió fue la de tratar de delimitar el contenido y significado de la expresión "materiales didácticos". Con frecuencia observamos que se toman en sentido unívoco expresiones tales como: materiales didácticos, instrumentos didácticos, medios didácticos, etc.

Aunque sólo sea por cuestión de procedimiento y como metodología de análisis, yo voy a diferenciar a los unos de los otros. Llamaré materiales didácticos a todo el aparato conceptual, es decir, al conjunto de contenidos y conocimientos que un equipo docente trata de transmitir a un amplio espectro de alumnos. Y voy a llamar medios o instrumentos didácticos al vehículo o canales de comunicación empleados, para poner en contacto a los alumnos con dichos materiales. Pienso yo que ambos aspectos deben de ser abordados, el tratar un tema de este tipo, en una universidad y enseñanza a distancia como la nuestra

La segunda duda que me surgió, al reflexionar sobre esta cuestión, es la de: ¿Cómo podemos valorar o evaluar estos materiales y medios didácticos? Opino, al respecto que caben dos posibilidades: $1 .{ }^{\circ}$ ) Hacerlo 
mediante una evaluación externa o auditoría (como quizás llamarían algunos), $2^{\circ}$ ) Hacerlo, por el contrario, mediante una evaluación interna, en la que los propios docentes deciden valorar y contrastar sus materiales y medios didácticos. Tomar esta segunda decisión supone articular los procedimientos y el sistema para poder llevarlos a cabo.

En mi opinión personal la primera de las posibilidades está abocada al fracaso, por varias causas:

1. a Los docentes somos bastante renuentes a que critiquen nuestra actividad quienes no intervienen en la misma. No nos gustan, definitivamente, las auditorías.

2. ${ }^{\text {a }}$ Al ser bastante críticos, siempre nos surge la duda de: $Y$, ¿quién evalúa a los evaluadores?

3. - La experiencia nos demuestra que tales auditorías o evaluaciones externas son, en ocasiones, interesadas u ocultan intereses no siempre confesables.

Por todo ello, naturalmente, intuyo que en la enseñanza deben de aplicarse procedimientos de evaluación interna. En éstos, el propio equipo docente: 1) Decide y consensúa la realización de este chequeo, tratando de alcanzar determinados objetivos, 2) Arbitra los procedimientos y la sistemática para realizarlos, 3) Una vez realizado el mismo, y detectados los éxitos y fracasos de sus materiales o medios, lleva a cabo un proceso de retroalimentación para cambiar lo que no funciona.

La tercera duda que me surgió fue ésta: ¿Qué referencias o parámetros elegir para valorar nuestros materiales y medios didácticos? Yo entiendo que al movernos en una Universidad de carácter público, como es fundamentalmente la UNED, y competir con otras formas de Universidad y de Enseñanza, debemos elegir dos parámetros de carácter empresarial: la rentabilidad y la competitividad. Naturalmente, ambos parámetros habrían de entenderse no en sentido economicista, sino estrictamente docente. Es decir, nuestros materiales y medios didácticos son buenos, si son rentables y útiles para aquéllos a los que van destinados: los alumnos. $Y$ su bondad se incrementará, si compiten con los materiales y medios de otras instituciones, etc., de enseñanza.

\section{CARACTERISTICAS DE UNOS BUENOS MATERIALES DIDÁCTICOS}

Todo buen material didáctico deberá de someterse a una cuádruple adecuación: a) Adecuación a los alumnos que aprenden, b) Adecuación a 
las exigencias científicas, técnicas y profesionales de la materia a aprender, c) Adecuación a la modalidad de enseñanza aprendizaje, en este caso, de la enseñanza a distancia, d) Adecuación en cuanto a la coherencia interna y eficacia de dichos materiales.

En la enseñanza en que nos movemos y en nuestras disciplinas de Geografía nos encontramos, frecuentemente con unos alumnos adultos que, cuando inician el estudio de las mismas, carecen del hábito de aprender a estudiar. Han de compaginar el estudio con otras obligaciones de adultos. Deben de mantener la motivación y superar las dificultades del curso, así como adquirir la seguridad personal y afrontar los cambios. Pues bien, en este contexto, un buen Equipo docente habrá de procurar que los contenidos de la materia, sin olvidarse del rigor científico, les sean presentados a los alumnos de forma motivadora, facilitándoles la comprensión de los mismos en forma de conversación didáctica guiada; es decir, conviene, como dice Holmberg upresentar los materiales y contenidos de forma clara, orientar al alumno sobre lo importante y accesorio de cada tema, invitándole emotivamente mediante el uso de un estilo personal y coloquial...". En resumen, que quien elabora los materiales didácticos, debe de poner el énfasis en el que aprende (el alumno) y cómo aprende éste, pero sin olvidarse jamás de que el propio alumno deberá de hacerse cargo de su propio aprendizaje.

Pues bien, hacer todo esto, que no es poco, es procurar buscar la rentabilidad y competitividad de los materiales didácticos. $Y$ nuestro Departamento de Geografía, a lo largo de una ya dilatada trayectoria de años ha puesto un gran empeño, pienso yo, en este objetivo. Sus materiales, entendidos como aparato conceptual o conjunto de conocimientos y contenidos a enseñar de las disciplinas geográficas, se han ido enriqueciendo, depurando y revisando, año tras año. Sin abandonar su carácter científico, han procurado adaptarse a las necesidades y demandas de los alumnos, acercándose a lo que los pedagogos llaman enseñanza activa, con carácter más práctico y de mayor calidad. Este tipo de enseñanza, como nos dice Kaplun: "parte del alumno como destinatario, de las experiencias y necesidades de éste para, una vez reformuladas pedagógicamente y científicamente, devolvérselas en forma de conocimientos".

Creo que éste debe de ser el itinerario a seguir por cualquier Departamento Universitario, que elabore materiales didácticos para sus alumnos. Y sólo cuando el espectro de usuarios supere el marco de su umbral natural de alumnos, podremos decir que esos materiales poseen el 
marchamo de la rentabilidad y competitividad de los mismos. En nuestro caso, nos consta, muchos de los materiales de este Departamento están siendo utilizados ya por alumnos de la Universidad presencial o licenciados, que preparan sus oposiciones de Enseñanza Secundaria.

\section{CARACTERISTICAS DE UNOS BUENOS MEDIOS DIDÁCTICOS}

La búsqueda de unos adecuados medios didácticos es otro de los retos de cualquier Departamento Universitario, para vehicular los conocimientos de una forma rentable y competitiva hacia los alumnos.

Pero todo buen equipo docente, al elegir éstos, habrá de tener en cuenta el tipo de conocimientos y disciplinas a enseñar, así como las necesidades y preferencias de los alumnos.

Hagamos un breve escarceo por algunos de estos medios y veamos sus ventajas e inconvenientes:

\section{Los medios impresos}

Del variopinto conjunto de medios que se pueden elegir, los medios impresos (Unidades didácticas, guias didácticas, etc., y textos de todo tipo), pienso yo, siguen siendo medios muy adecuados, rentables y competitivos para la enseñanza de la Geografía. Algunos sin embargo, piensan que con las nuevas tecnologías de la información y la informática estos medios han dejado de ser rentables y eficaces en la enseñanza. Yo, como Eduardo Ramos Méndez, en su artículo "Metodología, Medios y Tecnología en la UNED", opino que las nuevas tecnologías, más que acabar con los medios impresos lo que hacen es potenciarlos, al abaratar su proceso de edición.

La supervivencia de estos medios tienen razones varias: 1. .) Una histórica. No podemos olvidar que la imprenta tiene más de 500 años, y éstos han hecho que dicho medio sea familiar para el intelectual y el estudiante. 2..9) El texto impreso necesita de poca infraestructura para sernos útil, si acaso un rincón cómodo y buena luz. 3.a) La estructura de transmisión del conocimiento en él es lineal, se realiza sin grandes saltos ni ramificaciones, y esto, facilita la comprensión a los alumnos. 4. ${ }^{a}$ ) Caben gran cantidad de conocimientos en poco espacio y su producción es relativamente económica. 
Pero este medio tiene, también, limitaciones grandes para nuestras disciplinas: no puede incluir aspectos que tengan que ver con el movimiento, el sonido, ni la simulación de procesos o la interacción con los alumnos.

\section{Los medios audiovisuales}

En una enseñanza a distancia como la nuestra, la incorporación de estos medios, dota a la misma de unos estupendos instrumentos complementarios de los anteriores.

\section{La radio y los cassettes de audio}

Son medios muy adecuados para grabar o dar conferencias, lecciones magistrales, noticias sobre la marcha del curso o aspectos claves de los programas de estudio. Su facilidad, económica y versatilidad los hace instrumentos complementarios de los medios impresos. Sin embargo, la ausencia de imagen y la reducida o nula interacción entre el docente y el discante reducen la rentabilidad de los mismos.

\section{Los cassettes de vídeo}

Al incorporar imágenes y sonido aportan al alumno esos elementos practicos, que tanto necesitan éstos, para la comprensión de algunos temas. Su riesgo, sin embargo, está en la quizás desconexión con el resto de los medios.

\section{La televisión}

Al incorporar imágenes de todo tipo, reales y animadas, abre un abanico de posibilidades enormes en disciplinas como la Geografía. Pero los costes de producción de cualquier programa televisivo, convierten a este medio en inviable. Para Ricardo Marín en su artículo "La integración de los Medios Tecnológicos en las Universidades a Distancia" este medio sólo resulta rentable cuando el umbral de alumnos supera los 150 mil. 


\section{Los medios informativos}

La novedad de estos medios, y las posibilidades técnicas que ofrecen, han provocado que algunos docentes hayan pensado en los mismos como la panacea que ha de resolver los problemas del proceso de enseñanzaaprendizaje. Pero la realidad no es tan sencilla. Ya hay estudios fiables sobre el tema, como el de ROBIN MASON, de la Open University Británica, quien, tras estudiar cómo 1.200 alumnos podian conectar sus ordenadores con el de la Open University, llegó a la conclusión de que: “La Comunicación interactiva era la única razón de ser de este medio".

Pues bien, tras este rápido recorrido por algunos de los medios didácticos, yo me atrevería a decir lo siguiente:

El gran reto de un Departamento como el nuestro, es saber elegir los medios adecuados para cada disciplina y para cada uno de los temas. Seguir apostando por los medios impresos y la mejora de éstos sigue siendo muy rentable y competitivo. Continúan, pienso yo, siendo medios muy eficaces, ya que permiten al alumno reflexionar y madurar en la comprensión de la estructura conceptual, metodología, etc., de las disciplinas geográficas. No olvidemos, además que tres cuartas partes de tiempo que los alumnos destinan al aprendizaje en la UNED, lo dedican a los materiales impresos.

Potenciar la elaboración de medios complementarios como los vídeo cassettes, a posar del riesgo de desconexión con otros medios, seguirá siendo muy rentable y competitivo, por la capacidad de éstos para potenciar los anteriores (los impresos).

Pero el gran reto o debate de futuro, para un Departamento como éste, pienso yo, será el elaborar un organigrama en cada una de las disciplinas de medios integrados; es decir, el hacer un uso combinado de los medios más adecuados para cada tema o unidad didáctica. Y ello supondrá, el tener que definir la utilización proporcional de cada medio, para cada unidad temática. Sólo así, opino, habremos conseguido la máxima rentabilidad y competitividad de éstos. 